\title{
OS CONTRABANDISTAS DO PENSAMENTO - IMPASSES DA CRÍTICA LITERÁRIA BRASILEIRA NO FINAL DO SÉCULO XIX
}

\author{
Maria Lúcia Outeiro Fernandes*
}

A literatura nacional, que outra coisa é senão a alma da pátria, que transmigrou para este solo virgem com uma raça ilustre, aqui impregnou-se da seiva americana desta terra que lhe serviu de regaço; e cada dia se enriquece ao contato de outros povos e ao influxo da civilização?

José de Alencar

A

crítica e a história literária, enquanto mediadoras entre os produtores de bens simbólicos e o público, regulam a oferta e o consumo dos produtos reconhecidos como "literários". ${ }^{1}$ Mais que isso, legitimando tais produtos como representantes do sistema de normas, convenções e padrões literários de um determinado momento, numa dada cultura ou sociedade, ambas

* Unesp - Araraquara - SP

1 BOURDIEU, P. A economia das trocas simbólicas. São Paulo: Perspectiva, 1979. p. 15 . 
FERNANDES, M. L. O. Os contrabandistas do pensamento...

- a história e a crítica - atuam como relevantes instâncias de consagração desses produtos e participam da própria construção dos sistemas estabelecidos, influenciando diretamente a formação dos cânones literários.

O esforço para criar uma crítica literária brasileira gerou dupla necessidade para os autores do século passado: determinar os objetivos da crítica e, ao mesmo tempo, estabelecer a definição e a caracterização do que deveria ser compreendido como "literatura brasileira". Apesar das divergências, verificamse, entre os principais autores do período, algumas preocupações em comum diante de problemas teóricos e metodológicos. A principal delas é o desejo de construir uma literatura verdadeiramente autônoma e original.

O projeto de uma literatura nacional não é contribuição exclusiva dos críticos realistas. Já estava presente nos principais debates e propostas dos autores românticos. Como demonstra Antonio Candido, ${ }^{2}$ a construção do cânone literário brasileiro instaura-se a partir do anseio de criar uma tradição literária, tendo por perspectiva os horizontes estabelecidos pelas concepções românticas de gênio artístico, bem como de criação e obra literária enquanto expressões dessa subjetividade - ora enfatizando-se o aspecto individual da subjetividade, ora tomando o indivíduo como síntese de um espírito coletivo, quer essa idéia de "coletivo" se refira a uma época ou a uma nacionalidade. Objetivando a informação e a sistematização histórica, a crítica romântica tentou elaborar uma história literária "que exprimisse a imagem da inteligência nacional na sequiência do tempo". Gerações de críticos, eruditos e professores trabalharam reunindo textos, editando obras e pesquisando biografias, num projeto de construção de um passado literário que tornaria viável, no decênio de 1880, a obra de Sílvio Romero, História da Literatura Brasileira, uma das primeiras concretizações daquele ideal romântico de sistematizar o passado, estabelecendo as bases de uma tradição literária própria.

Coube à geração realista a avaliação da posição de cada obra dentro dessa tradição, o que, segundo Wellek, deveria ser "a primeira tarefa da história literária" 3. Para os historiadores do período realista-naturalista, essa tarefa não deveria prescindir da crítica. Mas a grande novidade trazida pelos principais críticos dessa fase foi a retomada do projeto nacionalista aliado ao projeto de uma crítica literária análoga às ciências naturais.

Verificar como os principais críticos dessa fase - Machado de Assis, Sílvio Romero, José Veríssimo e Araripe Júnior - posicionam-se em relação a

2 CANDIDO, A. Formação da literatura brasileira. São Paulo: Edusp, 1975. v. 1, p.

3 WELLEK, R.; WARREN, A. Teoria da literatura. [S. 1.]: Publicações Europa-América, 1976. p. 324. 
esse duplo projeto, comparando as suas contribuições para a construção de uma epistemologia crítica e, sobretudo, para a definição e a caracterização da literatura brasileira e, conseqüentemente, para a fixação de um cânone que desse suporte a esses construtos, é o objetivo deste trabalho. Entre as questões teóricas que irão direcionar a discussão do assunto proposto, destacam-se: o caráter historicizável dos conceitos de literatura, periodização e literatura nacional; as complexas relações entre história, contexto cultural e discurso; e os compromissos ideológicos dos autores.

\section{O equilíbrio neoclássico em Machado de Assis}

Numa carta escrita a Machado de Assis, ${ }^{4}$ no dia 22 de fevereiro de 1868, José de Alencar exalta a abnegação do colega, que dedica seu talento para "formar o gosto e desenvolver a literatura pátria", classificando-o como o "primeiro crítico brasileiro".

A observação de José de Alencar não é inteiramente destituída de veracidade, pois, com Machado de Assis, inicia-se no Brasil uma crítica literária em que a valoração das obras começa a disputar espaço com os assuntos biográficos, que até então haviam predominado no discurso crítico. Respondendo a José de Alencar, a 1. ${ }^{\circ}$ de março de 1868, Machado confessa-se desiludido quanto aos esforços que empreendera para fazer de sua obra crítica uma contribuição à "reforma do gosto":

...não podiam impedir o tremendo desastre [...] o mal vinha de fora e se impunha ao espírito literário do país ainda mal formado e quase sem consciência de si. [...] Era difícil plantar as leis do gosto, onde se havia estabelecido uma sombra de literatura, sem alento nem ideal, falseada e frívola, mal imitada e mal copiada. Nem os esforços dos que, como V. Ex., sabem exprimir sentimentos e idéias na língua que nos legaram os mestres clássicos, nem esses puderam opor um dique à torrente invasora. ${ }^{5}$

4 MACHADO DE ASSIS, J. M. Correspondência. Rio de Janeiro: Lackson, 1946a.

5 MACHADO DE ASSIS, op. cit., p. 23. 
FERNANDES, M. L. O. Os contrabandistas do pensamento...

A atenção de Machado concentra-se em dois aspectos básicos: o estado incipiente do "espírito literário do país" e a artificialidade de uma literatura importada de modo superficial. Consciente de seu papel para uma literatura em fase de formação, Machado inclui, entre os objetivos do exercício crítico, o questionamento sobre o "espírito nacional" das obras literárias.

Eclético, seu discurso fundamenta-se em tradições clássicas, mas absorve propostas românticas, mostrando-se aberto às renovações realistas. $\mathrm{O}$ peso de suas concepções teóricas sobre forma, herdadas do século XVIII, permite que seja classificado como um crítico de formação neoclássica, que define como um dos principais objetivos da crítica o de verificar se o escritor faz "obra de arte" ou "obra de passatempo". ${ }^{6}$

A rigidez em relação à forma se revela quando Machado, rejeitando funções não estéticas para a obra, estabelece, por exemplo, que a arte não deve ser cópia da natureza, nem da história e nem deve ter a preocupação de demonstrar teorias e idéias. Isso não o impede, porém, de adotar o conceito de arte de Victor Hugo, atribuindo à obra literária uma missão social, nacional e humana. Daí se conclui que Machado também rejeita o conceito de "arte pela arte", admitindo que o escritor, em seus textos literários, possa protestar contra as injustiças sociais, desde que não extrapole as "condições da arte", ou seja, a "emoção e o belo".?

Além de iniciativa civilizadora, a arte deve ser um "culto nacional", cabendo ao escritor o talento para tirar "das entranhas do assunto e do tempo aquilo [...] que é digno da arte, fazendo-se imaginoso e intérprete". ${ }^{8}$ Uma das funções do crítico seria a de guiar o autor nessa difícil tarefa. A ausência de uma crítica fecunda, que se identifique com a análise imparcial, coerente, sincera e independente, e que obedeça a duas condições básicas - ciência e consciência constitui, segundo o crítico, um dos "maiores males" da produção literária do país. ${ }^{9}$ Se a arte tem a relevante função de "assinalar, como um relevo na história, as aspirações éticas do povo - e aperfeiçoá-las e conduzi-las para um resultado de grandioso futuro", não seria possível "aspirar a um grande passo na civilização" ${ }^{10}$ sem uma arte orientada de maneira segura, conclui ele.

Embora veja na poesia, como na arte em geral "alguma coisa inalterável, universal e comum, que fala a todos os homens e todos os tempos", ${ }^{11}$ considera

6 MACHADO DE ASSIS, J. M. Crítica literária. Rio de Janeiro: Jackson, 1946 b. p. 62.

7 MACHADO DE ASSIS, J. M. Crítica teatral. Rio de Janeiro: Jackson, 1946c. p. 268.

8 MACHADO DE ASSIS, 1946a, op. cit., p. 199.

9 MACHADO DE ASSIS, 1946c, op. cit., p. 140.

10 MACHADO DE ASSIS, 1946a, op. cit., p. 20.

11 MACHADO DE ASSIS, 1946b, op. cit., p. 329. 
que a arte também precisa refletir seu contexto social: "O que se deve exigir do escritor, antes de tudo, é certo sentimento íntimo, que o torne homem do seu tempo e do seu país, ainda quando trate de assuntos remotos no tempo e no espaço". ${ }^{12}$ Cabe ao artista buscar esse equilíbrio. Mas compete ao crítico orientálo nessa busca.

As reflexões de Machado de Assis que envolvem o questionamento sobre universal e nacional refletem posições teóricas do século XVIII, que abordavam a literatura em três níveis: a literatura universal, a comparada e a nacional. Tais reflexões vão levar o autor a tratar de questões como a influência estrangeira, a independência da literatura brasileira, as fontes de inspiração e os assuntos, a caracterização do povo e de sua literatura.

Reconhecendo na literatura brasileira um instinto de nacionalidade, que atua desde o início, preparando sua independência, Machado analisa a contribuição de cada movimento para dar uma fisionomia própria ao pensamento brasileiro, mas critica duramente o excesso de nacionalismo de alguns setores da crítica literária no Brasil, mostrando que se equivocavam ao confundir descrições de aspectos exteriores com espírito nacional: "Um poeta não é nacional só porque insere nos seus versos muitos nomes de flores ou aves do país, o que pode dar uma nacionalidade de vocabulário e nada mais." 13

Machado enfatiza a idéia de que o elemento "assunto" não é suficiente para caracterizar qualquer obra literária como nacional. É preciso que ela apresente aquele "sentimento íntimo", ou seja, toda aquela carga subjetiva que alimenta o comportamento de um povo e de uma nação. Esse conceito sobre a índole do povo, bastante adiantado para a época, pode ser relacionado com a teoria de Taine, para quem o conceito de "raça" inclui as características psicológicas de um povo. Segundo Aderaldo Castelo, esse conceito poderia ser comparado com o que hoje se entende em termos de ideologia, de sentimento, de caráter que marcam o comportamento de um povo e de uma nação. ${ }^{14}$

Embora nunca abandone as preocupações com questões estéticas, ao analisar vários autores, de diferentes épocas, sua preocupação fundamental é verificar a contribuição das obras para o debate desse tema. Em 1873, redige uma espécie de "balanço" sobre a literatura brasileira, publicado em $O$ Novo Mundo, de Nova Iorque, tentando traçar os caminhos futuros dessa produção e

12 MACHADO DE ASSIS, 1946b, op. cit., p. 139.

13 Id.

14 Idéias reconstituídas a partir de anotações feitas durante as aulas ministradas pelo professor e crítico literário, José Aderaldo Castelo, durante o curso "Evolução das Idéias Críticas na Literatura Brasileira, Século XIX: período realista”, no Instituto de Estudos Brasileiros da Universidade de São Paulo, no segundo semestre de 1978. 
descobrir o perfil do brasileiro, subjacente a essa literatura. O escritor, conclui Machado de Assis, precisa do nacional para atingir o universal, ou seja, deve captar aquilo que é "permanente" no seu povo.

Apesar da constante busca de um equilíbrio, coerente com a formação neoclássica de seu autor, a obra crítica de Machado de Assis padece de algumas contradições, decorrentes dos impasses entre as idéias importadas e a necessidade de construir os cânones de uma literatura brasileira independente. De um lado, rejeita o abuso do nacionalismo na produção literária brasileira, mas, de outro, reconhece o potencial enriquecedor e universalizador das idéias e doutrinas estrangeiras, embora também condene a cópia indiscriminada. Consciente do valor estético da obra, sua crítica ainda se filia à estética romântica, que confere à arte missão civilizadora. Comprometendo-se excessivamente com dados biográficos, Machado concentra-se nas figuras que poderiam dar suporte a uma tradição literária e a uma definição do caráter brasileiro. Apesar de pregar o ideal da imparcialidade, seu discurso crítico se caracteriza pelo tom pessoal, intimista - é freqüente referir-se aos escritores como "colegas" 15 -, denunciando simpatias e admirações particulares, além de revelar as limitações próprias de uma crítica escrita para periódicos.

\section{As ambiguiidades de Sílvio Romero}

As contradições de Sílvio Romero ${ }^{16}$ ficaram conhecidas na história da literatura brasileira pelas inúmeras polêmicas que causaram. A crítica atual, fazendo um balanço de sua obra, tende a valorizá-la justamente por este aspecto duplo, definindo-o como expressão de uma dinâmica criatividade. É o caso de Antonio Candido que, além de justificar tais contradições, demonstra ter sido o autor sempre fiel a certas idéias centrais. Para entendê-lo, diz Candido, seria necessário:

...não querer reduzi-lo às suas contradições nem proclamar a sua perfeita unidade; e sim procurar compreender o seu ritmo de turbilhão [...] o movimento de analisar, compreender e construir

15 MACHADO DE ASSIS, 1946b, op. cit., p. 326.

16 As contradições de Sílvio Romero, segundo Dante Moreira Leite, "resultam da aceitação de teorias incompatíveis e, ao mesmo tempo, de sua inadequação à realidade conhecida pelo autor." (LEITE, 1976, p. 188) 
não se separava de um movimento simultâneo de destruir; e essa dualidade indissolúvel dá certo cunho revolucionário ao seu pensamento, mesmo quando surgem pela frente as antinomias conservadoras, que também compunham o movimento de ir-evir do seu turbilhão. ${ }^{17}$

Antonio Candido ressalta as principais idéias do autor: a visão da sociedade brasileira como produto da mestiçagem, o problema do indianismo, do nacionalismo, os condicionamentos da literatura, o papel da crítica, os métodos críticos, a caracterização da literatura brasileira, o relacionamento da ciência com a arte e da literatura com a sociedade, entre outros. Como já fizera Machado de Assis, Sílvio Romero também aponta a dependência espiritual em relação ao influxo externo:

A vida espiritual brasileira é pobre e mesquinha [...]. À força de desprezarmos a corrente de nossa própria história e pormo-nos fora do curso das idéias livres, eis-nos chegados ao ponto de não passarmos de ínfimos glosadores das vulgaridades lusas e francesas; eis-nos dando o espetáculo de um povo que não pensa e produz por si. ${ }^{18}$

Lamenta profundamente que não haja, no Brasil, uma crítica definida como "ciência e disciplina do espírito", que poderia garantir um futuro melhor para o país, salvando os brasileiros do fato de não terem vida própria e de serem obrigados a viver como uma espécie de "contrabandistas do pensamento".

Deixando de lado os problemas exclusivamente estéticos, Romero propõe-se a fazer uma crítica social ampla, com o objetivo de desenvolver a consciência intelectual e nacional do brasileiro:

A crítica moderna não é a antiga crítica literária; é uma disciplina científica que se aplica a todas as manifestações da humani-

17 CANDIDO, A. Introdução. In: ROMERO, S. Teoria, crítica e história literária. São Paulo: Edusp, 1978. p. XI.

18 ROMERO, S. Teoria, crítica e história literária. São Paulo: Edusp, 1978. p. 4. 
FERNANDES, M. L. O. Os contrabandistas do pensamento...

dade. [...] Seu domínio é o da criação e da inteligência humana [...] e por isso ela chama-se crítica histórica. ${ }^{19}$

Em sua História da Literatura Brasileira ${ }^{20}$ enfatiza que não pretende fazer simples apreciação estética, mas deseja realizar uma história das idéias "história do pensamento brasileiro". Expondo com detalhes o seu projeto, explica que deveria ser uma "história natural das letras brasileiras", ou seja, uma pesquisa sobre as condições do "determinismo literário", para compreensão das "leis" que haviam determinado - e continuavam determinando - o processo de formação do gênio e do caráter do povo brasileiro. Outra finalidade seria a de atualizar o pensamento produzido no país em relação à produção teórica e científica do "mundo culto" da época. Fornece esclarecimentos sobre os métodos e critérios de análise que pretende utilizar, enfatizando o elemento "étnico", as idéias positivistas e o darwinismo, um aglomerado teórico que ele próprio denomina como sendo uma "bifurcação spenceriana do evolucionismo":

A lei que rege a literatura é a mesma que dirige a história em geral: a evolução transformista. Ela habilita-se a formular a síntese do universo e da humanidade, síntese que não é puramente objetiva, como quiseram sempre os empiristas de todos os tempos, nem exclusivamente subjetiva, como sempre declamaram os idealistas de todas as épocas. A síntese é complexa, bilateral, transformista em totalidade, não só dos elementos ideais e abstratos, como dos naturais e empíricos. ${ }^{21}$

O conceito de literatura adotado por Sílvio Romero é amplo o suficiente para compreender "todas as manifestações da inteligência de um povo", abrangendo a política, a economia, as criações populares, as ciências e as artes. Sua análise dessa produção cultural mostra-a como resultante de três fatores: o meio, a raça e as correntes estrangeiras. $\mathrm{O}$ meio, segundo ele muito atuante e presente na literatura brasileira, refere-se ao aspecto geral da natureza e sempre impulsiona os processos de caracterização racial.

19 ROMERO, 1978, op. cit., p. 87.

20 ROMERO, S. História da literatura brasileira. 6. ed. Rio de Janeiro: J. Olympio, 1960. $5 \mathrm{v}$.

21 Ibid., p. 100. 
O conceito de raça, para Sílvio Romero, seria um conjunto de características morais e culturais: preferências, índole, temperamento psicológico, idiossincrasias, enfim, todos os elementos da cultura, uma espécie de sinônimo aglutinador de outros termos da mesma área semântica como povo, cultura e civilização.

Baseada na idéia de uma interação entre raça e cultura, a noção de causalidade, um princípio fundamental para as concepções racionalistas que adota como métodos de análise, não tem sentido mecânico nos textos de Sílvio Romero. As causas naturais, segundo ele, não se limitariam a uma atuação de fora para dentro, pois as forças produzidas pela cultura são tão importantes quanto as determinações naturais.

Embora os adote como ferramentas teóricas, Romero considera os três fatores de Taine - raça, meio e momento - insuficientes para revelar e esclarecer "o segredo dos gênios e das letras", ${ }^{22}$ enfatizando, constantemente, que todo crítico literário precisa estudar esses três fatores sem perder de vista outro elemento primordial, que seria a individualidade do artista, concebida por ele como uma síntese final das influências externas. A literatura, como toda arte, é um produto cultural do homem e a personalidade do artista - uma espécie de protótipo da raça - deveria ser o principal objeto de investigação do crítico.

Embora condene a arte pela arte, também não aceita as finalidades práticas como motivações válidas para a expressão artística, por considerar que a arte - como o direito e a linguagem -, uma vez constituída, deve caminhar por si mesma, autônoma, tendo por única finalidade o belo. Entretanto, como produto cultural, a produção artística deveria exercer um papel de elevação do homem.

A literatura faz pelo sentimento o que a ciência faz pela razão: liberta o homem e estimula-o a sonhar e trabalhar para um estado melhor; uma melhor confiança em nossos desígnios, em nossas faculdades, em nosso futuro. ${ }^{23}$

É dever do escritor construir sua obra sobre os dados da observação, não para formular teses, mas para compreender o "jogo das paixões", compreensão

22 ROMERO, 1978, op. cit., p. 39.

23 Ibid., p. 100. 
FERNANDES, M. L. O. Os contrabandistas do pensamento...

essencial para qualquer artista. Deve, também, assimilar, da ciência, as conclusões e os fins, para não dizer tolice:

O poeta, como homem de seu tempo, há de, por força, respirar no ambiente de sua época, há de entrar na corrente espiritual do período humano que atravessa, e daí o interesse que todos os grandes artistas revelam sempre pelos sérios problemas que lhes foram coevos. ${ }^{24}$

A "crítica científica" é o propósito mais enfatizado pelo autor. Quase sempre, porém, seu discurso carece da objetividade, do rigor da análise em profundidade, da apreciação impessoal e desapaixonada, da concisão e clareza, ou seja, de critérios adequados ao discurso científico, tal como o que é proposto em seu projeto crítico. Desviando-se das intenções iniciais de fazer "obra científica", perde-se em divagações e considerações puramente impressionistas. O termo "científico", em seu discurso, fica restrito à tentativa de aplicação de métodos e sobretudo de terminologia, emprestados das ciências naturais, para uma "darwinização" da crítica.

Propõe uma teoria da literatura brasileira como produto das características raciais e sociais do país, cuja sociedade se distingue sobretudo pelo fenômeno da mestiçagem. Seja no sangue ou nas idéias, todo brasileiro é um mestiço, conclui Sílvio Romero:

É indispensável convir que o tipo, a encarnação perfeita do genuíno brasileiro, como a seleção biológica e histórica o tem produzido, por enquanto, está na classe de mestiços de toda a ordem na sua imensa variedade de cores [...] Esta fusão ainda não está completa, e é por isso que ainda não temos um espírito, um caráter inteiramente original. ${ }^{25}$

24 ROMERO, 1978, op. cit., p. 140.

25 Ibid., p. 68. 
Uma literatura deve ser "a expressão do estado emocional e intelectual de um povo". Sendo a sociedade brasileira produto de forças diferenciadoras que a tornaram cada vez mais distinta da portuguesa, o nacionalismo literário o principal problema da literatura brasileira - só pode ser corretamente configurado pelo estudo da mestiçagem. Nacionalismo não é o pitoresco temático. Nem pode ser confundido com uma das três raças separadamente. Nacionalismo significa, então, assimilação profunda das características do país, para gerar um estado de espírito e de sensibilidade, ou seja, um modo de ser. E o estudo da literatura brasileira deve ser o estudo da "caracterização do brasileiro" em face do português.

O preconceito de raça é relevante na análise que Sílvio Romero faz sobre a contribuição de negros e índios para a formação do povo e da cultura no Brasil. Aspectos desagradáveis ou degradantes são enfatizados na descrição de costumes e formas de comportamento. A todo momento enfatiza a necessidade de manter a imigração européia como forma de branqueamento da população. Considera que o mestiço é uma transição necessária para um "tipo superior".

Utilizando conceitos hoje superados, como o de "raça superior", Sílvio Romero é pessimista quanto à população do Brasil, apontando-lhe uma série de características negativas como apatia, falta de iniciativa, desânimo, abatimento intelectual, irritabilidade, nervosismo e imitação do estrangeiro. Caindo em contradição, porém, ele próprio estabelece como quadro referencial para o trabalho da crítica e da produção literária em geral a necessidade de imitar o que qualifica, do alto do seu racionalismo europeizante e centralizador, como "povos mais adiantados".

\section{A ótica do colonizador no discurso de José Veríssimo}

José Veríssimo parece muito seguro quando afirma que a finalidade da arte é comover. E que a literatura, para ser arte, deve apresentar certas "virtudes intrínsecas", entre as quais a mais importante, capaz de conferir à obra um valor permanente, seria a de provocar emoções. De acordo com o racionalismo positivista, adotado pelo autor, as emoções humanas permanecem sempre as mesmas.

Ao longo de suas análises e reflexões, entretanto, a singela segurança de tal argumentação dilui-se em meio a impasses e divagações. Na construção de seu objeto de investigação, num processo que passa por diversas fases, marcadas 
FERNANDES, M. L. O. Os contrabandistas do pensamento...

por diferentes opções intelectuais, ${ }^{26}$ o próprio crítico deixa transparecer a necessidade de incorporar, em seu discurso, um instrumental teórico mais complexo, que lhe permita articular os problemas específicos da produção literária brasileira com as teorias e métodos em voga na Europa - o positivismo, o darwinismo, o evolucionismo e outras correntes -, que José Veríssimo agrupa sob o rótulo de "idéias modernistas".

Embora busque a valorização da literatura na própria obra, Veríssimo combate o esteticismo, rejeitando também o excesso de subjetivismo: "A arte não é uma invenção pessoal. É o produto de uma emoção individual sim, mas social e humana", ${ }^{27}$ princípio que também norteia a concepção que o autor adota para definir a arte literária: "Expressão do modo de pensar e de sentir de um povo e de uma época, as literaturas hão de por força variar, conforme o povo e a época a que pertencem, e só são notáveis quando refletem a civilização em cujo seio foram geradas." 28

O universalismo adotado por José Veríssimo não o desviou do confronto "escritor versus sociedade", típico de sua época. ${ }^{29}$ Para José Veríssimo é estranha a idéia de uma literatura que não seja realista por natureza:

Mas realista no alto sentido de que deriva diretamente das grandes realidades, das verdades universais, fundamentais e superiores da vida, do homem. [...] Observar, em arte não é somente ver e descrever; é principalmente distinguir aspectos novos nos fenômenos observados, e aspectos de que o artista tire efeitos estéticos inéditos. ${ }^{30}$

O meio, em cuja formação influem causas geográficas, históricas e morais, por ser um dos fatores condicionantes da literatura, precisa oferecer certas condições favoráveis. No Brasil, as falhas do "meio" - a deficiência do ensino,

26 BARBOSA, J. A. Introdução. In: VERÍSSIMO, J. Teoria, crítica e história literária. São Paulo: Edusp, 1977.

27 VERÍSSIMO, J. Estudos de literatura brasileira; 1. a série. São Paulo: Edusp, 1976. p. 132.

28 VERÍSSIMO, J. Teoria crítica e história literária. Rio de Janeiro: Livros técnicos e científicos, 1977f. p. 203.

29 Uma das preocupações centrais do pensamento positivista foi determinar o grau de responsabilidade do escritor em relação ao seu contexto social. (Cf VERÍSSIMO, J. Estudos de literatura brasileira; 6. ${ }^{\text {a }}$ série. São Paulo: Edusp, 1977e.).

30 VERÍSSIMO, 1976, op. cit., p. 96. 
a falta de cultura, o desinteresse pelas coisas do país - geram, de um lado, o despreparo dos escritores, que se revela na falta de um espírito filosófico e de ideais humanos elevados ${ }^{31} \mathrm{e}$, de outro lado, geram também a indiferença do público. As maiores conseqüências desse círculo vicioso de falhas e deficiências são: a tendência para imitar tudo o que é estrangeiro, a ausência do hábito de reflexão, a carência de idéias próprias e de sinceridade. Tudo isso, conclui Veríssimo, resulta numa literatura sem qualquer originalidade.

As deficiências culturais brasileiras dificultam o aparecimento de uma literatura nacional. A falta de uma tradição de pensamento, por exemplo, seria responsável pela redução da poesia brasileira a um subjetivismo exagerado, alheio ao que é social: "os escritores [...], sem comunhão com o seu povo, com a sua nação, são forçados também a viver espiritualmente fora dela", ${ }^{32}$ alimentando-se do pensamento e da emoção alheia. A imitação, porém, não apresenta, para José Veríssimo, apenas aspectos negativos:

Todas [as literaturas], as mais ricas, vivem de escambos de idéias e concepções. Somente nós não trocamos, apenas recebemos. Nem podemos pretender uma literatura original, não tendo nem podendo ter, um pensamento original. É a França, e, em segundo grau, Portugal que tem fornecido idéias, moldes, inspirações ao nosso pensamento literário. ${ }^{33}$

Reflexo da sociedade brasileira - uma sociedade incaracterística, formada de elementos heterogêneos e sem tradição própria - , a literatura só poderia ser também uma literatura incaracterística. ${ }^{34}$ Feitas com inteligência e critério, as imitações das grandes obras estrangeiras, sobretudo de suas qualidades, poderiam fortalecer o pensamento nacional, enriquecendo a produção literária.

Tentando delinear o caráter nacional, Veríssimo analisa os três elementos básicos de sua formação: o português, o tupi e o negro. Salienta, porém, que só o português contribuiu para a formação da literatura brasileira. O índio e o negro teriam contribuído de modo indireto, por meio da mestiçagem, atuando

31 VERÍSSIMO, J. Estudos de literatura brasileira: 2. 'serie. São Paulo: Edusp, 1977a. p. 105 .

32 VERÍSSIMO, 1977f, op. cit., p. 57.

33 VERÍSSIMO, J. Estudos de literatura brasileira: 3. a série. São Paulo: Edusp, 1977b. p. 17.

34 Ibid., p. 65. 
FERNANDES, M. L. O. Os contrabandistas do pensamento...

como fatores da variedade étnica que é o brasileiro. De qualquer forma, seria impossível determinar os elementos com que cada um deles entrou para a formação da psique brasileira:

Para se compreender perfeitamente o espírito de um povo é necessário estudar bem os diferentes elementos que o compõem. É sobre esse critério que assentamos o nosso modo de pensar de que é do estudo bem feito dos elementos étnicos e históricos de que se compõe o Brasil, da compreensão perfeita do nosso estado atual, de nossa índole, de nossas crenças, de nossos costumes e aspirações que poderá sair uma literatura que se passa a chamar conscientemente brasileira, à qual ficará reservado o glorioso destino de fazer entrar este país, pela forte reação de que falamos atrás, numa nova via de verdadeira civilização e progresso. ${ }^{35}$

José Veríssimo ainda hesita em chamar a produção literária do Brasil de literatura brasileira, considerando-a apenas como um ramo da portuguesa: "Certamente essa literatura merece o nome de brasileira, como designação regional. Ela é portuguesa não só pela língua, mas pela inspiração, pelo sentimento, pelo espírito". ${ }^{36}$

Embora reconheça a persistência, no tempo e no espaço, de certo espírito nativista, seguido de um sentimento nacional, que confere a essa produção relativa unidade, ${ }^{37}$ Veríssimo esbarra no problema da língua, tomando-o como entrave à autonomia literária. Como elemento constituinte das literaturas, a língua é "a expressão do que há de mais íntimo, de mais individual, de mais característico em um povo. Só têm literatura própria [...], original, os povos que têm língua própria". ${ }^{38}$

Tal como fizeram Machado de Assis e Sílvio Romero, José Veríssimo também critica o nacionalismo que se identifica com assuntos locais. O legítimo nacionalismo literário é o que se identifica com um "inconsciente sentimento nacional, feito com os instintos etnográficos, com os instintos históricos, com

35 VERÍSSIMO, 1977f, op. cit., p. 162.

36 Ibid., p. 62.

37 Ibid., p. 80.

38 Ibid., p. 63. 
os instintos tradicionais, que nenhuma cultura, que nenhuma aspiração cosmopolita consegue destruir ou sequer apagar". 39

Atribuindo ao exercício crítico uma função pedagógica, Veríssimo aponta inúmeras falhas não somente na esfera da produção e recepção literária, mas em todos os níveis da cultura brasileira. ${ }^{40}$ Apontar falhas na sociedade brasileira é um procedimento que ele partilha com os demais críticos da fase realista-naturalista, o que demonstra o caráter didático e autoritário de uma posição iluminista, centralizadora, mas também revela o desejo de criar uma linguagem crítica que pudesse direcionar não somente a produção literária, superando o caráter descritivo e de exaltação da crítica romântica, mas que também pudesse intervir no próprio sistema social, exercendo uma eficaz missão civilizadora.

Sempre criticando a valorização do estrangeiro, exagerada pelos brasileiros, José Veríssimo apresenta uma visão bem negativa de tudo o que é nacional, estabelecendo constante e desfavorável confronto com os costumes, formas de comportamento e produção artística estrangeira. Em sua opinião, o povo brasileiro carece de originalidade e se caracteriza como excessivamente romântico e sentimental, inculto, pouco civilizado, chegando mesmo a ser primitivo, inimigo da leitura e do trabalho exaustivo. Inteligente mas preguiçoso, o brasileiro também é vaidoso, imaginativo, sensual e melancólico. O trabalho intelectual, no contexto do país, é prejudicado pela incapacidade para o pensamento abstrato, pela vaidade e mania de erudição: "assim como em filosofia e ciência somos inaptos para cogitacões abstratas e generalizações fecundas, somos por igual impróprios para as criações artísticas que demandem capacidades eficientes de observação, de análise, de generalizações e de síntese". ${ }^{41}$

\section{Araripe Júnior: um precursor das vanguardas tropicalistas}

Araripe Júnior foi o primeiro crítico a valorizar a parte original da cultura brasileira, chegando a reconhecer nela um estilo tropical. É difícil destacar sua concepção de literatura brasileira, pois não escreveu uma história compacta dela. Mas formulou uma teoria que tem o mérito de, como ressalta Alfredo Bosi, relacionar fenômenos estéticos, psicológicos e socioculturais, na tentativa

39 VERÍSSIMO, 1977b, op. cit., p. 155.

$40 \mathrm{O}$ conceito de cultura em José Veríssimo se restringe à produção de conhecimento elevado, bem como às idéias e crenças de um povo.

41 VERÍSSIMO, 1976, op. cit., p. 96. 
FERNANDES, M. L. O. Os contrabandistas do pensamento...

de analisar as propriedades formais das obras, apontando como sua origem "a dinâmica existencial do próprio autor em face das tradições". ${ }^{2}$

Apesar de todo esforço na busca de uma interpretação original da literatura brasileira, o próprio crítico, consciente de estar adotando instrumental teórico importado, aponta o ecletismo de sua metodologia:

O método que adotei, na preparação deste ensaio, é o mesmo que tenho seguido desde 1878. Orientado no evolucionismo spenceriano e adestrado nas aplicações de Taine, procurei depois fortalecer-me no estudo comparado dos críticos vigentes. Todos os pontos de vista da exegese moderna têm sido objetivo de minhas preocupações.[...] Devo declarar também que muito continuo a aprender relendo Aristóteles, Longino, Horácio e principalmente Quintiliano. ${ }^{43}$

Mesmo as doutrinas estrangeiras, quando transplantadas para o Brasil, sofrem, segundo ele, uma inevitável aclimatação. É o que deve ocorrer, por exemplo, com o naturalismo, uma das correntes de grande prestígio no momento:

A nova escola [...] tem de entrar pelo trópico de Capricórnio, participando de todas as alucinações que existem no fermento do sangue doméstico, de todo o sensualismo que queima os nervos do crioulo. O realismo, aclimando-se aqui, como se aclimou o europeu, tem de pagar o seu tributo às endemias dos países quentes, aonde, quando o veneno atmosférico não se resolve na febre amarela, na cólera, transforma-se em excitações medonhas, de um dantesco luminoso. ${ }^{44}$

42 BOSI, A. Introdução. In: ARARIPE JÚNIOR. Teoria, crítica e história literária. São Paulo: Edusp, 1978.

43 ARARIPE JÚNIOR. Teoria, crítica e história. São Paulo: Edusp, 1978. p. 280.

44 Ibid. 
Suas hipóteses a respeito das adaptações e transformações sofridas pelos portugueses e estrangeiros ante a paisagem nativa e o modo de vida tropical, levam Alfredo Bosi a classificá-lo como precursor das vanguardas tropicalistas.

Supervalorizando o fator "meio" na formação de um caráter nacional e na produção artística e literária, Araripe Júnior se deixa contaminar completamente pelo fascínio que ele próprio sente diante da natureza tropical:

De impressões completamente estranhas, de uma natureza tão cheia de esplendores como a da América, dessas florestas seculares, desses rios colossais, não deve por certo surgir senão uma literatura original, melancólica e ao mesmo tempo pasmosa, impregnada desse poderosíssimo sentimento religioso que por si só se expande toda vez que o homem curva-se ante o Senhor, abismado pelos portentos da criação. ${ }^{45}$

A "incorreção" - visível no estilo e no uso da língua -, constantemente denunciada pelos críticos, está ligada ao espírito da terra e, longe de ser defeito, é uma verdadeira "qualidade". Decorrente do fenômeno da obnubilação, essa incorreção confere originalidade à literatura aqui produzida:

O tropical não pode ser correto. A correção é o fruto da paciência e dos países frios; nos países quentes, a atenção é intermitente [...]. O estilo, nesta terra, é como o sumo da pinha, que, quando viça, lasca, deforma-se e pelas fendas irregulares, poreja o mel dulcíssimo, que as aves vêm beijar; ou como o ácido do ananás do Amazonas, que desespera de sabor, deixando a língua verter sangue, picada e dolorida. É esse estilo desprezado pelos rigoristas que justamente me apraz encontrar na mocidade que agora surge no Brasil [...]. Acode-me que a literatura brasileira, nas suas manifestações legítimas, não pode, tão cedo, ser uma literatura simétrica e disciplinada, senão uma convulsão entremeada de longos períodos de repouso, de languidez. E, demais, isto não é fato recente, de longa data este fenômeno de desordem tropical se fez sentir. ${ }^{46}$

45 ARARIPE JÚNIOR, op. cit., p. 10.

46 Ibid., p. 126-129. 
FERNANDES, M. L. O. Os contrabandistas do pensamento...

Cerne de suas reflexões sobre o Brasil e sua produção estética e cultural, o fenômeno curiosamente definido como "obnubilação brasílica", uma lei que determina uma gradativa subordinação dos elementos da civilização à terra brasílica, numa constante perda de características originais desses elementos, explica a originalidade do caráter brasileiro e permite a Araripe Júnior libertarse, em parte, do negativismo e do complexo de inferioridade visíveis no discurso da crítica produzida no Brasil nas últimas décadas do século XIX:

A esse fenômeno, durante o qual, como se vê, adelgaçaram-se, atenuaram-se todos os comandos de hábitos que subordinavam o homem à civilização, abriu-se uma fenda na estratificação da natureza civilizada, para dar passagem à poderosa influência do ambiente primitivo; a esse fenômeno, que se acentua a cada passo no movimento da vida colonial ou aventureira do século XVI, poder-se-ia dar o nome de obnubilação brasílica, e, sem dúvida, sobre ele basear-se toda a teoria histórica daquela época indeci$\mathrm{sa}^{47}$

Desse modo, Araripe Júnior procura caracterizar o brasileiro em função de seu meio, de sua realidade natural e cultural. "Cada caráter assimila, do ambiente que o cerca, tudo quanto lhe é assimilável, e repele o resto, exatamente como a planta, que observa os elementos necessários para a composição da seiva" ${ }^{48}$ E o estilo de cada escritor seria resultante do conflito entre o temperamento de cada indivíduo e o mecanismo das formas literárias já criadas por um povo, por um grupo ou por uma escola.

Embora aponte características negativas no brasileiro - sensual irrequieto, vítima do entusiasmo fácil, do desejo de brilhar -, não o desvaloriza, mas, pelo contrário, é bastante otimista. Não é desprezando o brasileiro e seu contexto social, conclui ele, que se vai conseguir nacionalizar a cultura e a produção literária do país, em busca da tão almejada liberdade em relação ao "velho continente".

Tal como seus colegas anteriores, lamenta profundamente a imitação estrangeira e a ignorância dos jovens que, desapegados "das coisas pátrias", ${ }^{9}$

47 BOSI, op. cit.

48 ARARIPE JÚNIOR, op. cit., p. 145.

49 Ibid., p. 18. 
ignoram completamente as "cenas dignas de grandes epopéias", que povoam a história de suas origens, sobretudo as cenas da luta do colono com a excêntrica índole do indígena, ou seja, do embate da civilização com a selvageria. A imitação, conclui Araripe, não se limita às letras: a população das capitais vive uma "vida de empréstimos". Seria necessário esperar que, das regiões menos contaminadas pela civilização, saísse a elaboração nacional que acabaria por caracterizar o elemento nacional:

...não é baldado o esforço com que se tenta nacionalizar a nossa literatura. Um movimento extraordinário agita o país e elementos poderosos se congregam, se combinam para fazer emergir a pátria do estado embrionário em que as circunstâncias até agora a conservam [...] A poesia, entretanto, no meu fraco pensar, não pode deixar de ceder, ou mais cedo, ou mais tarde, à influência do clima, do aspecto do país e da índole de seus primitivos habitantes. ${ }^{50}$

O problema do nacionalismo se relaciona com o fenômeno da obnubilação. No próprio Anchieta, por exemplo, "vemos o misticismo diluir-se em um curioso naturalismo e a sua teologia transformar-se genialmente em fetichismo para realizar a obra da catequese dos índios". ${ }^{51}$

O indianismo foi uma etapa importante no desenvolvimento desse fenômeno: "a semente plantada pelo autor do "Guarani" frutificou; e, atualmente, quer entre gramáticos, quer entre literatos, romancistas e poetas, nota-se uma salutar tendência por esse Ipiranga das letras". José de Alencar representa, na literatura brasileira, o início da busca de uma realidade tipicamente nacional, diferente da realidade do homem civilizado. A integração do brasileiro ao mundo civilizado, porém, depende da conquista dessa autonomia nacional das letras, que inclui a própria expressão linguiística. Tal como seus colegas, Araripe também cai em contradição ao apontar a imigração como um dos fatores que vai auxiliar o brasileiro nessa integração universal, fornecendo-lhe exemplo de "atividade inteligente".

50 ARARIPE JÚNIOR, op. cit., p. 9.

51 Ibid., p. 311. 


\section{A busca do caráter nacional}

A busca de uma identidade nacional, na tradição literária brasileira, responde à necessidade de caracterização de uma produção própria da colônia, cujos agentes desejam sempre alcançar dois objetivos aparentemente irreconciliáveis: de um lado, a fidelidade à metrópole cultural, que lhes poderia assegurar espaço nos cânones da literatura universal; e, de outro, a busca de uma originalidade, apoiada nos elementos característicos da terra, que lhes conferisse o privilégio de fundarem uma literatura nacional.

Nos anos 20, no calor das discussões modernistas, que procuravam construir as bases para uma literatura autônoma, utilizando duas vigas mestras, duas traves de sustentação - as novas estéticas européias, com que se pretendia derrubar o passadismo das letras e das artes no país, e a pesquisa das carcterísticas nacionais, com que se almejava conquistar uma expressão artística original e assegurar a tão sonhada independência cultural -, Mário de Andrade, consciente de estar retomando ideais românticos, direciona suas reflexões estéticas para a busca de um caráter nacional, que ele próprio denomina como uma "entidade psíquica permanente, se manifestando por tudo, nos costumes, na ação exterior, no sentimento, na língua, na História, na andadura, tanto no bem como no mal" ${ }^{52}$ Segundo Mário, o nacionalismo estético seria indispensável como fase inicial de uma arte brasileira que ainda estava se formando no país. A meta final, entretanto, seria a de chegar naturalmente a uma integração na arte universal. Arte pura e desinteressada era coisa inútil num país onde tudo tinha que ser feito. E arte interessada significava arte nacional, voltada para a realidade do país..$^{53}$

A partir dos debates modernistas, os estudiosos da literatura brasileira habituaram-se, em geral, a tratar o período realista-naturalista como uma fase em que a preocupação com o nacional esteve ausente. Enfatizou-se a idéia de um retorno "à tradição romântica, que havia dado início a uma arte nacional". ${ }^{54}$ Dessa forma, legitimou-se, entre os intérpretes da produção nacional, um modelo totalizador e maniqueísta para a leitura dos períodos literários brasileiros.

De acordo com as perspectivas dicotômicas predominantes, ${ }^{55}$ ora supervalorizam-se os modelos fornecidos pelos centros hegemônicos, menos-

52 ANDRADE, M. Prefácio. In: LOPES, T. P. A. Macunaíma: a margem e o texto. São Paulo: Hucitec, 1974. p. 87.

53 Em sua obra $O$ banquete, Mário discute amplamente esse tema. Cf. ANDRADE, M. $O$ banquete. São Paulo: Duas Cidades, 1977.

54 ANDRADE, 1974, op. cit., p. 316.

55 YUDICE, G. Postmodernity and capitalism in Latin America. Revista Brasileira de Literatura Comparada, Niterói, v. 1, p. 87-109, 1991. 
prezando-se as produções da colônia como meras cópias, pálidos reflexos, imitações inferiores; ora, de acordo com projetos revolucionários de emancipação política, econômica e cultural, prega-se a ruptura, valorizando-se as obras pelo que trazem de original.

Foi no século XIX, com o debate entre românticos e realistas que esse modelo maniqueísta se consolidou nas análises do país e da sua produção artística. As obras dos quatro críticos estudados foram essenciais para o estabelecimento desse modelo. Mas também foram as maiores vítimas dele. Em primeiro lugar, pelos impasses que esse modelo trouxe para suas próprias análises da literatura brasileira. Em segundo lugar, porque, pela perspectiva dicotômica, coube-lhes, na interpretação modernista da história literária brasileira, o papel de simples contrabandistas do pensamento, para usar um termo aplicado por Sílvio Romero aos intelectuais e artistas brasileiros.

Quando se repensa a questão da identidade nacional e da caracterização da literatura brasileira, adotando um modelo que, problematizando as relações entre o centro e as margens, supera as dicotomias, a exemplo do que foi proposto por Silviano Santiago, num ensaio que já se tornou clássico nos estudos de literatura brasileira, ${ }^{56}$ pode-se verificar como a apropriação dos códigos da civilização européia não se fez sem uma constante transfiguração em suas normas, o que lhes destruía, sistematicamente, a unidade, a pureza e, conseqüentemente, o "sinal de superioridade cultural".

Os quatro autores estudados parecem estar em constante diálogo com as principais questões da arte literária surgidas ao longo do processo de construção de um sistema literário autônomo nas sociedades européias: como a questão do antigo e do novo - é bom lembrar como José Veríssimo se referia às novas doutrinas como "idéias modernistas" e como todos enfatizam a necessidade de atualização em relação à produção européia - ou a questão do universal e do nacional.

Machado de Assis, Sílvio Romero, José Veríssimo e Araripe Júnior apresentam temas e discussões que remontam a questionamentos estéticos próprios do século XVIII. Tendo iniciado sob os ruídos da célebre Querela entre Antigos e Modernos, esse período vai se configurar, na história do Ocidente, como aquele em que intelectuais e artistas tentam articular a idéia de um belo universal - que se mantinha em consonância com os valores da Antiguidade Clássica - com o conceito de um belo relativo, próprio de cada época. ${ }^{57}$

56 SANTIAGO, S. O entre-lugar do discurso latino-americano. In: Uma literatura nos trópicos: ensaios sobre dependência cultural. São Paulo: Perspectiva, 1978. p. 11-28.

57 JAUSS, H. R. Tradição literária e consciência atual da modernidade. In: OLINTO, H. K. Histórias de literatura: as novas teorias alemãs. São Paulo: Ática, 1996. p. 47-100. 
FERNANDES, M. L. O. Os contrabandistas do pensamento...

No século XIX, essa consciência histórica se amplia, articulando-se com o conceito de nacionalismo. Como observa Costa Lima, ${ }^{58}$ a institucionalização do estudo da literatura sobre o princípio da nacionalidade demonstrava a vitória de uma corrente de reflexão romântica, cujo denominador comum girava em torno da função social da arte. Analisando o discurso de alguns autores românticos, como Coleridge, Shelley e Schiller, Costa Lima procura o elo entre a função estética - umas das forças centrais da justificação da arte na modernidade - e o princípio da nacionalidade, concluindo: "o papel reconciliador do homem com a natureza atribuído à arte só poderia ser alcançado pelas nações civilizadas". E, o "cidadão civilizado se caracterizaria pela interiorização da alma nacional". ${ }^{59}$

Em diferentes perspectivas, os quatro críticos aqui estudados - Machado de Assis, Sílvio Romero, José Veríssimo e Araripe Júnior - partilham a idéia de que, para atingir o universal, precisam formar um pensamento nacional. Tal como vai dizer também, mais tarde, Mário de Andrade.

Machado de Assis, por exemplo, observador atento do caráter brasileiro, não se deteve na procura de explicações e causas para as características que vê no brasileiro - como fizeram seus colegas -, limitando-se a apontá-las de modo disperso. Acabou concluindo, pela intuição, que o brasileiro estava mais próximo do primitivo do que do civilizado. Ou, segundo suas palavras, o brasileiro estava ainda na "infância da civilização".

Na Europa, semelhantes idéias justificaram o imperialismo sobre os povos tidos como "não civilizados". No Brasil, motivaram a busca de uma superação das condições nacionais adversas - falta de pensamento próprio, falta de interesse pelos autores brasileiros, falta de identidade definida - e de uma ascensão a um "estágio superior" de pensamento e de produção artística. Convencidos da necessidade de colocar o Brasil em contato com reflexões e métodos novos, os críticos dessa geração adotam doutrinas, valores e critérios europeus no estudo da literatura brasileira. Coerentes com o papel civilizador que atribuem à crítica e à arte, empreendem um estudo dos elementos que caracterizariam o homem e a sociedade brasileiros e conseqüentemente, sua literatura - vista como um reflexo do contexto -, já que o ingresso na civilização dependia, conforme estabeleciam os discursos críticos europeus, da internalização dos elementos nacionais.

58 LIMA, L. C. O controle do imaginário e a literatura comparada. In: ROCHA, J. C. C.; COSTA, L. V. (Ed.). Literatura comparada: questões e perspectivas. Rio de Janeiro: UERJ, 1995. (Cadernos do Mestrado/Literatura, 1).

59 LIMA, op. cit., p. 49-50. 
Os impasses com que se depararam, redundando freqüentemente em contradições e falácias na construção de seus discursos críticos, já significam que não se limitaram a copiar os discursos europeus.

O ecletismo de doutrinas e métodos revela o esforço para encontrar uma síntese com que pudessem estabelecer as bases de uma crítica eficaz no cumprimento de sua complexa missão. Os conceitos de crítica, arte, história literária e literatura brasileira por eles formulados também estavam atrelados a esse ideal.

Apesar do positivismo e do evolucionismo presentes na obra dos quatro autores, o modelo implícito em seu discurso crítico, romântico em seu idealismo subjetivo, foi herdado de seus antecessores. O que desejavam, segundo João Alexandre Barbosa ${ }^{60}$ como "ideólogos da classe média ascendente", era uma intervenção no próprio sistema social, visando a sua regeneração. Ingenuamente, fizeram do culto da inteligência e da erudição suas armas de combate.

As contradições, decorrentes, em parte, da adoção de teorias tão diversas e, em parte, da própria complexidade da missão a que se obrigaram, já revelam as fissuras estabelecidas no arcabouço teórico importado. Tal como nas colagens pop, os fragmentos teóricos tirados de diferentes fontes, quando colocados lado a lado, influenciam-se mutuamente, gerando novos significados, que alteram inevitavelmente os originais.

O único que se permitiu ir além das fissuras, chegando a lançar as bases para uma leitura da literatura brasileira como expressão de um "estilo tropical" - Araripe Júnior -, acabou sucumbindo à rigidez do modelo legitimado por essa geração: o modelo dicotômico que opunha, de um lado, as idéias importadas e, de outro, os elementos nacionais. Não pôde deixar de reconhecer a superioridade do estrangeiro, colocando-os como modelos a serem seguidos.

\section{RESUMO}

O esforço para criar uma crítica literária brasileira, bem como uma literatura autônoma e original, gerou uma dupla necessidade para os autores do século XIX: determinar os objetivos da crítica e estabelecer a definição e a caracterização da literatura brasileira. O objetivo deste trabalho é verificar como os principais críticos da fase realista-naturalista - Machado de Assis, Sílvio Romero, José Veríssimo e Araripe Júnior

60 BARBOSA, J. A. A tradição do impasse: linguagem da crítica e crítica da linguagem em José Veríssimo. São Paulo: Ática, 1974. p. 60. 
FERNANDES, M. L. O. Os contrabandistas do pensamento...

- posicionam-se em relação a esse duplo projeto, comparando as suas contribuições para a construção de uma epistemologia crítica, sobretudo para a definição e a caracterização da literatura brasileira e, conseqüentemente, para a fixação de um cânone que desse suporte a esses construtos. Entre as questões teóricas que direcionam a discussão do assunto proposto, destacam-se: o caráter histórico dos conceitos de literatura, periodização e literatura nacional; as complexas relações entre história, contexto cultural e discurso; e os compromissos ideológicos dos autores.

Palavras-chave: Crítica literária brasileira, realismo-naturalismo, formação da literatura brasileira.

\section{ABSTRACT}

The endeavour to create a Brazilian literary criticism, and also an autonomous literature, brought before the 19th century critics a double requirement: clarify the objectives aimed by criticism as well as define and characterize Brazilian literature. This work aims at examining how the realistic and naturalistic critics - Machado de Assis, Sílvio Romero, José Veríssimo e Araripe Júnior - stand with regard to that double project, by comparing their contributions for the construction of a critical epistemology, above all for the definition and characterization of Brazilian literature and, as a result, for fixing a canon that could support those constructs. Among the theoretical questions that steer the discussion about the proposed subject, the article emphasizes: the historical character of the concepts like literature, periodicity and national literature; the intricate connections between history, cultural context and discourse; and the ideological engagement of the authors.

Key-words: Brazilian literary criticism, realism-naturalism, Brazilian literature formation. 


\section{REFERÊNCIAS}

ANDRADE, M. Prefácio. In: LOPES, T. P. A. Macunaíma: a margem e o texto. São Paulo: Hucitec, 1974.

. O banquete. São Paulo: Duas Cidades, 1977.

. Carta aberta a Alberto de Oliveira. Estética, ed. fac-similar. Rio de Janeiro: Gernasa, 1974.

ARARIPE JÚNIOR. Teoria, crítica e história literária. São Paulo: Edusp, 1978.

ALENCAR, J. Bênção Paterna. In: Sonhos de ouro. [s. 1: s. n.], [19-?]. p. 34.

ANDRADE, M. Prefácio para Macunaíma. In: LOPES, T. P. A. Macunaíma: a margem e o texto. São Paulo: Hucitec, 1974.

BARBOSA, J. A. A tradição do impasse: linguagem da crítica e crítica da linguagem em José Veríssimo. São Paulo: Ática, 1974.

Introdução. In: VERÍSSIMO, J. Teoria, crítica e história literária. São Paulo: Edusp, 1977. p. IX-XXXVII.

BOSI, A. Introdução. In: ARARIPE JÚNIOR. Teoria, crítica e história literária. São Paulo: Edusp, 1978.

BOURDIEU, P. A economia das trocas simbólicas. São Paulo: Perspectiva, 1979.

CANDIDO, A. Formação da literatura brasileira. São Paulo: Edusp, 1975. v. 1, p. 348-356.

. Introdução. In: ROMERO, S. Teoria, crítica e história literária. São Paulo: Edusp, 1978. p. IX-XXX.

JAUSS, H. R. Tradição literária e consciência atual da modernidade. In: OLINTO, H. K. Histórias de literatura: as novas teorias alemãs. São Paulo: Ática, 1996. p. 47-100.

LEITE, D. M. O caráter nacional brasileiro: história de uma ideologia. 3. ed. São Paulo: Pioneira, 1976.

LIMA, L. C. O controle do imaginário e a literatura comparada. In: ROCHA, J. C. C.; COSTA, L. V. (Ed.). Literatura comparada: questões e perspectivas. Rio de Janeiro: UERJ, 1995. (Cadernos do Mestrado/Literatura, 1). 
FERNANDES, M. L. O. Os contrabandistas do pensamento...

MACHADO DE ASSIS, J. M. Correspondência. Rio de Janeiro: Jackson, 1946a.

. Crítica literária. Rio de Janeiro: Jackson, $1946 b$.

. Crítica teatral. Rio de Janeiro: Jackson, 1946c.

ROMERO, S. Teoria crítica e história literária. São Paulo: Edusp, 1978.

. História da literatura brasileira. 6. ed. Rio de Janeiro: J. Olympio, 1960. 5 v.

SANTIAGO, S. O entre-lugar do discurso latino-americano. In: . Uma literatura nos trópicos; ensaios sobre dependência cultural. São Paulo: Perspectiva, 1978. p. 1128

VERÍSSIMO, J. Estudos de literatura brasileira: 1ª série. São Paulo: Edusp, 1976. . Estudos de literatura brasileira: $2^{\mathrm{a}}$ série. São Paulo: Edusp, 1977a. . Estudos de literatura brasileira: $3^{\text {a }}$ série. São Paulo: Edusp, 1977 b. . Estudos de literatura brasileira: 4ª́rie. São Paulo: Edusp, 1977c. . Estudos de literatura brasileira: 5ásérie. São Paulo: Edusp, 1977d. . Estudos de literatura brasileira: 6ª́série. São Paulo: Edusp, 1977e. $\overline{1977 f}$. Teoria, crítica e história literária. Rio de Janeiro: Livros Técnicos e Científicos,

WELLEK, R.; WARREN, A. Teoria da literatura. [S. 1.]: Publicações Europa-América, 1976.

YUDICE, G. Postmodernity and capitalism in Latin America. Revista Brasileira de Literatura Comparada, Niterói, v. 1, p. 87-109, 1991. 